\title{
OS PROGRAMAS DE CRÉDITO AGRÍCOLA E DE FOMENTO PARA A AGRICULTURA FAMILIAR: UMA ANÁLISE ACERCA DO PRONAF E DO PNAE
}

\author{
Marana Sotero de Sousa ${ }^{1}$ \\ André Gomes de Sousa Alves ${ }^{2}$
}

\section{RESUMO}

O presente estudo tem como intuito demonstrar a importância das políticas de crédito e de fomento para a agricultura familiar, não apenas para o desenvolvimento da própria atividade agrícola familiar, mas principalmente, busca associar crédito e fomento, objetivando verificar que ambos, juntos, auxiliam igualmente para o desenvolvimento econômico também do setor rural brasileiro, contribuindo, reflexamente, para a diminuição da fome e da pobreza no Brasil. Para o desenvolvimento do estudo, utilizou-se do método de abordagem qualitativo, aprofundando uma análise sobre políticas públicas e agricultura familiar, consistindo também em pesquisa exploratória, utilizando-se igualmente de revisão bibliográfica.

Palavras-chave: Políticas públicas de crédito; políticas públicas de fomento; agricultura familiar; PRONAF; PNAE.

\section{THE AGRICULTURAL CREDIT AND FAMILY FARMING PROGRAMS: AN ANALYSIS OF PRONAF AND PNAE}

\begin{abstract}
The purpose of this study is to demonstrate the importance of credit and development policies for family agriculture, not only for the development of family farming activities, but also to seek to associate credit and development with the purpose of verifying that both together help for the economic development of the Brazilian rural sector, contributing, reflectively, to the reduction of hunger and poverty in Brazil. For the development of the study, the method of qualitative approach was used, deepening an analysis on public policies and family agriculture, also consisting of exploratory research, also using a bibliographical review.
\end{abstract}

Keywords: Public credit policies; public development policies; family farming; PRONAF; PNAE

\section{INTRODUÇÃO}

Para haver diminuição da pobreza rural e consequente desenvolvimento econômico, é necessária a atuação do Estado a fim de incentivar a produção agrícola. Com o incremento da

\footnotetext{
${ }^{1}$ Doutoranda em Ciências Jurídicas, pela Universidade Federal da Paraíba (UFPB). Mestre em Ciências Jurídicas, pela Universidade Federal da Paraíba (UFPB). Especialista em Gestão Pública Municipal e Especialista em Educação em Direitos Humanos, ambas pela Universidade Federal da Paraíba (UFPB). Graduada em Direito, pelas Faculdades Integradas de Patos-PB (FIP). Professora do Curso de Direito das Faculdades Integradas de Patos (FIP).

${ }^{2}$ Doutor em Ciências Jurídicas, pela UFPB. Doutorado-sanduíche, pela Universidade do Minho-Portugal. Mestre em Ciências Jurídicas, pela UFPB. Especialista em Gestão Pública Municipal, pela UFPB. Graduado em Direito, pela UFPB. Professor do Curso de Direito das FIP e da UFCG.
} 
produção, é possível obter o lucro. Porém, na maioria das vezes aqueles que podem produzir não possuem ou não dispõem dos recursos necessários para incrementar sua atividade produtiva, necessitando adquirir capital (dinheiro) junto a instituições bancárias. Desta maneira, o crédito surge como instrumento propulsor da circulação de produções.

Os bancos, principais instituições concessoras de crédito, desempenham importante papel nesse ciclo produtivo por disporem do principal agente, o dinheiro. São os grandes responsáveis pela distribuição do crédito e, para tanto, utilizam-se de diversas fontes de recursos. Possuindo condições financeiras, o produtor rural detém meios de adquirir insumos que a atividade econômica requer, fazendo com que sua produção aconteça, gerando riquezas que serão ampliadas e que precisarão cada vez mais de capital para se expandirem, formando um ciclo de crescimento econômico.

O crédito é tido como importante ferramenta no desenvolvimento econômico do setor rural, configurando-se, pois, como um tipo de ação que estimula a atividade agrícola, além de contribuir para a diminuição dos índices de pobreza e de êxodo rural.

O crédito rural brasileiro teve início com os denominados financiamentos rurais, normatizados pela Lei $n^{\circ}$ 4.829/65. A partir daí, ressaltou-se a importância desse tipo de crédito para o crescimento econômico do país, fazendo surgir a necessidade de oferecer tratamento mais específico ao assunto, fator que implicou na criação do Sistema Nacional de Crédito Rural (SNCR), determinando a regulamentação do crédito e de suas formas de aplicação. O SNCR, juntamente com o Sistema Financeiro Nacional (SFN) e o Manual de Crédito Rural (MCR), disciplinam e normatizam o crédito rural e suas formas de concessão no âmbito das diversas atividades rurais brasileiras. Nessa perspectiva, um dos principais objetivos do crédito rural é o de fortalecer o produtor rural, dentre eles, o agricultor familiar.

A partir da década de 1980, com a crise econômica, iniciou-se no Brasil uma política restritiva, pautada na redução de subsídios financeiros e na desoneração do sistema de crédito formal, passando o Estado a admitir a participação do capital privado no financiamento agrícola. Com isso, aumentaram as reivindicações dos movimentos sociais rurais, associações agrícolas e sindicatos rurais exigindo a formulação de políticas públicas de crédito voltadas para a agricultura familiar, tendo em vista que esta categoria rural vinha ganhando espaço e importância nos últimos anos no Brasil devido à sua relevância para a segurança alimentar e para o desenvolvimento rural. 
Diante da necessidade de se formalizar e de disciplinar a atividade agrícola de cunho familiar, foi lançada, em 24 de julho de 2006, a Lei no 11.326 (Lei da Agricultura Familiar), que regulamentou a agricultura familiar, atribuindo-lhe status de atividade econômica.

Nesse cenário, faz-se igualmente necessário ressaltar a importância do Programa Nacional de Fortalecimento da Agricultura Familiar (Pronaf), criado através do Decreto $n^{\circ}$ 1946, de 28 de Junho de 1996. Trata-se da principal política pública, em nível federal, direcionada especificamente para a agricultura familiar, criada ainda no Governo Fernando Henrique Cardoso (FHC), mas apenas efetivada, aprofundada e consolidada durante os dois mandatos do Governo Lula (2003-2011) e continuada no Governo Dilma Rousseff (20112016). Entre outros objetivos, o programa visa a fortalecer o agricultor familiar, proporcionando-lhe aumento de sua renda e meios para incrementar o valor de seus produtos. Seu funcionamento, juntamente com a Lei da Agricultura Familiar, visa à garantia do crédito para o fomento da atividade agrícola de cunho familiar.

Nesse contexto, torna-se imprescindível analisar a confluência existente entre instituições financeiras, crédito rural, agricultura familiar, Pronaf, bem como as consequências advindas com o novo cenário político brasileiro e suas implicações para o desenvolvimento econômico do setor rural brasileiro e da própria atividade produtiva familiar.

Ao passo que se evidencia a importância do crédito para a atividade agrícola familiar, ressalta-se também a relevância das políticas públicas de fomento voltadas direta ou indiretamente para esta categoria rural. Tais políticas abarcam a promoção não apenas da própria agricultura familiar, mas buscam incentivar e assegurar, igualmente, outras áreas relacionadas com esta atividade rural, quais sejam, a alimentação adequada, a segurança alimentar e nutricional, além de procurar reduzir a pobreza e a miséria rural, bem como as desigualdades sociais e econômicas, a fim de obter o desenvolvimento econômico do setor rural brasileiro. São exemplos dessas políticas, em nível federal, o Programa Nacional de Alimentação Escolar (PNAE), o Programa de Aquisição de Alimentos (PAA), entre outros, os quais objetivam incrementar a produção, especialmente do agricultor familiar, disponibilizando meios para que o produtor saiba realizar o correto manejo da terra (através dos programas de extensão rural), auxiliando na distribuição e produção das sementes para o plantio (por meio dos programas de produção e distribuição de sementes), além de assegurar o produtor familiar contra as perdas de sua produção por ocasião das adversidades climáticas (possível graças a políticas públicas como o garantia-safra). 
Enfim, são políticas de fomento à agricultura familiar todas as que promovem, direta ou indiretamente, o incentivo à produção de cunho familiar, consistindo também em políticas que visam a melhorar e fortalecer o abastecimento interno do mercado brasileiro a partir do apoio à agricultura familiar, uma vez que este tipo de atividade agrícola é a responsável considerável pela alimentação interna do país.

No âmbito deste trabalho, as políticas públicas de crédito para a agricultura familiar estarão representadas pelo Pronaf, principal programa de crédito voltado para o produtor familiar. De seu turno, as políticas públicas de fomento para a atividade agrícola familiar estarão demonstradas, com maior ênfase, pelo PNAE.

Para o desenvolvimento do estudo que será adiante exposto, utilizou-se do método de abordagem qualitativo, tendo em vista consistir em análise que se preocupa em aprofundar uma compreensão a respeito da necessidade de impulsionar e incentivar as políticas públicas de crédito e de fomento voltadas para a agricultura familiar. Quanto aos objetivos, trata-se de uma pesquisa exploratória, pois objetiva deixar o problema do da fome e da segurança alimentar visíveis, colocando como hipótese provável a necessidade de uma maior atenção à agricultura familiar e às políticas públicas destinadas para a mesma, de modo a efetivar a alimentação adequada no Brasil, além de ser também uma pesquisa explicativa, uma vez que se preocupa em identificar a importância das mencionadas políticas públicas tanto para a própria atividade agrícola familiar, como para a garantia da segurança alimentar e alimentação adequada.

\section{O FINANCIAMENTO AgRÍCOLA BRASILEIRO E O CRÉDITO RURAL NO BRASIL: DA CRIAÇÃO DO SISTEMA NACIONAL DE CRÉDITO RURAL (SNCR) À LEI DA AGRICULTURA FAMILIAR}

O crédito diz respeito à transferência de propriedade de um bem, que pode ser temporária, considerando o retorno do bem ao proprietário originário após certo tempo, ou definitiva, em que há a transferência absoluta, ou seja, sem expectativa de retorno do bem. Sendo assim, a relação creditícia abrange três atores principais: o proprietário originário do bem (moeda/dinheiro), que o transfere para a instituição financeira (instituição intermediária), que, por sua vez, atua transferindo a um terceiro (devedor final) determinado bem a crédito. Esse crédito servirá para que esse ator final adquira bens de sua necessidade (MAFFIOLETTI, 2006, p. 239). 
Segundo Schumpeter (1997, p. 108-109), a importância prática do crédito, além de possibilitar o desenvolvimento, deve-se ao fato de carregar consigo "a possibilidade de empregar somas de dinheiro que estão temporariamente ociosas". O mencionado autor explica que a reação normal de todo homem que deseja produzir é tirar proveito dessas receitas ociosas e depois tomar emprestado o poder de compra. Essas somas em dinheiro permaneceriam ociosas e restritas a empresas e famílias enquanto delas não necessitassem, caso não houvesse nenhum tipo de desenvolvimento. O crédito é necessário para estimular a produção de uma atividade, gerando, consequentemente, o lucro.

No Brasil, as políticas públicas existentes geralmente se apegam aos recursos do governo ou a empréstimos de agentes externos como os únicos instrumentos capazes de impulsionar o desenvolvimento do âmbito rural. Por isso, faz-se importante analisar a importância atribuída ao crédito no planejamento governamental brasileiro voltado para o desenvolvimento de tal setor. Nesse contexto, o crédito consistiria em via apta para eliminar a pobreza rural, pois se configura como um tipo de ação pública que estimula a produção de bens, visando ao desenvolvimento do setor rural e da atividade agrícola, em especial (RODRIGUES, 2013).

O sistema de crédito brasileiro é fechado, concedido a um público exclusivo, formado por latifundiários capitalizados, com altas taxas de juros, envolvendo empréstimos de altos valores mediante onerosas exigências e garantias, além da análise criteriosa quando da sua concessão ao devedor (MAFFIOLETTI, 2006). A primeira atitude concreta para a obtenção de recursos para os financiamentos no setor agrícola adveio da autorização do Tesouro Nacional, em 09 de julho de 1937, por intermédio da Lei $n^{\circ} 454$, que elevou o capital do Banco do Brasil S.A. para permitir que os estabelecimentos bancários fornecessem crédito para obtenção de recursos necessários ao financiamento agrícola, pecuário e industrial (RODRIGUES, 2013).

Além do Banco do Brasil, outros bancos trabalharam o crédito rural, como o Banco do Estado de São Paulo, o Banco do Nordeste do Brasil (BNB) e o Banco de Crédito da Amazônia (BASA). Em 1964, os bancos privados também passaram a operar o crédito rural, com o uso de recursos disponibilizados pela Coordenação Nacional de Crédito Rural (CNRC), órgão adjunto ao Ministério da Agricultura. Não demorou para que o Banco Central do Brasil (BACEN) tomasse as atribuições da CNRC, chamando para si a responsabilidade de disciplinar a concessão de crédito rural no país (RODRIGUES, 2013). 
Os antigamente denominados "financiamentos rurais" tiveram sua normatização balizada na Lei $n^{\circ} 4.829 / 65$ que os institucionalizou, no Decreto $n^{\circ} 58.380 / 66$ que os regulamentou e no Decreto Lei no 167/67 que trata os Títulos de Crédito (PEREIRA, 2009). Tais disciplinamentos especiais dão ao crédito rural caráter extremamente peculiar, evidenciando a importância desse tipo de crédito na conjuntura econômica e social do país e despertando no legislador a necessidade de lhe fornecer tratamento mais direcionado e exclusivo, mediante legislação específica. Isso ficou elencado no art. 54 da Lei n ${ }^{\circ}$ 4.595/64, que criou o Sistema Nacional de Crédito Rural (SNCR) e determinou a regulamentação do crédito rural, bem como das modalidades de sua aplicação.

Contudo, foi apenas em 1949 que a política agrícola brasileira passou a perceber a importância do crédito como mecanismo promotor da agricultura e de fomento do meio rural, considerado fator fundamental nas políticas de desenvolvimento do país. Ademais, a partir de 1967, a proposta de empregar o crédito na agricultura foi institucionalizada pelo Estado brasileiro (BÚRIGO, 2007, p. 62).

\begin{abstract}
Assim, sob o império da Lei 4.829, de 05/11/65, o crédito rural foi institucionalizado e, sob esta nova ordem legal, apropriada e específica, o crédito se distinguiu de forma clara das demais linhas de crédito praticadas pelos agentes financeiros, o que se comprova pelo só fato da previsão do art. 21 da referida Lei que contemplou a aplicação compulsória de recursos pelos integrantes do sistema nacional de crédito rural (Lei $4.829 / 65$, art. $7^{\circ}$ ) diretamente no setor agropecuário, fato este não previsto na legislação ordinária que rege tanto o crédito comercial quanto o industrial, bem assim como outro qualquer (PEREIRA, 2009, p. 15).
\end{abstract}

O Manual do Crédito Rural (MCR) codifica as normas aprovadas pelo Conselho Monetário Nacional (CMN) e aquelas divulgadas pelo Banco Central do Brasil relativas ao crédito rural, às quais devem ser subordinados os beneficiários e as instituições financeiras que operam no Sistema Nacional de Crédito Rural (SNCR). O MCR considera crédito rural o suprimento de recursos financeiros, por instituições do Sistema Nacional de Crédito Rural (SNCR), para aplicação exclusiva nas finalidades e condições nele estabelecidas.

Dentre outros objetivos, o crédito rural visa a estimular o incremento ordenado dos investimentos rurais, inclusive para armazenamento, beneficiamento e industrialização dos produtos agropecuários, quando efetuado por cooperativas ou pelo produtor na sua propriedade rural. Visa também a favorecer o custeio oportuno e adequado da produção e a comercialização de produtos agropecuários, assim como busca possibilitar o fortalecimento econômico dos produtores rurais, notadamente os pequenos e médios, e incentivar a introdução de métodos racionais de produção, para o aumento da produtividade e melhoria do 
padrão de vida das populações rurais, além da adequada defesa do solo, conforme art. $3^{\circ}$ da Lei institucionalizadora.

Do objetivo principal do crédito rural, que é o de propiciar o fortalecimento econômico do produtor rural, destacam-se dois pontos fundamentais da Lei $\mathrm{n}^{\circ} 4.829 / 65$. O primeiro diz respeito ao suporte financeiro, na medida em que garante o crédito ao agricultor. Já o segundo ponto trata da instrumentalização do crédito, regulamentando o contrato a ser firmado entre o banco financiador e o produtor rural, posto que de nada adiantaria um crédito facilitado se o contrato fosse produzido mediante a inserção de cláusulas no interesse e arbítrio do financiador (PEREIRA, 2009).

Por tais motivos, a Lei do Crédito Rural estabeleceu que o Conselho Monetário Nacional (CMN) teria competência exclusiva para normatizar os financiamentos, competindolhe o estabelecimento de todas as condições do contrato, notadamente no que concerne à fixação dos juros (art. 14). A mencionada Lei, além de preocupar-se em fornecer e garantir o crédito, cuidou também de controlar e ditar os juros passíveis de serem contratados, atribuindo tal finalidade ao CMN, sabendo-se que, se o objetivo principal do crédito é o fortalecimento do produtor rural, é preciso garantir a este condições de pagar os juros estabelecidos no contrato, evitando, assim, que os bancos financiadores estipulem juros exorbitantes e impagáveis.

No Brasil, o Sistema Financeiro Nacional (SFN) é controlado pelo CMN, sendo constituído pelo Banco Central do Brasil (BCB), Comissão de Valores Mobiliários (CVM), Superintendência de Seguros Privados (Susep) e Secretaria de Previdência Complementar. Esses órgãos servem de apoio ao processo de regulamentação e fiscalização, igualmente funcionando na execução das diretrizes de programas públicos de crédito, estabelecendo a disciplina do crédito e buscando manter a estabilidade monetária com vistas ao desenvolvimento (MAFIOLLETTI, 2006, p. 237).

O Sistema Nacional de Crédito Rural (SNCR) teve sua organização realizada através da Resolução no 69, do Conselho Monetário Nacional, de 22 de setembro de 1967, apesar de sua criação ter ocorrido em 1964, com a criação da Lei $n^{\circ} 4.595$, tornando obrigatório o “direcionamento de $10 \%$ dos depósitos à vista no sistema bancário, para a concessão de crédito ao setor agrícola" (SILVA, 2006, p. 25). Igualmente, intencionava fornecer ao país uma estrutura de crédito rural que desse suporte às políticas de modernização encaradas pela agricultura brasileira. 
Entre 1995 e 1996, o quadro de desestímulo ao crédito rural se agravou, assim permanecendo até o final da década, quando não mais foi verificado o crescimento da liberação de valores ofertados pelo Sistema Nacional de Crédito Rural (REZENDE, 1985). A partir desse ponto, surgiu a necessidade de estimular novas formas de financiamento, que deram origem aos mecanismos semiformais e informais de recursos, os quais não estavam contidos no SNCR.

Assim como toda atividade econômica agrícola, a agricultura familiar está envolta e necessita de um mercado de crédito rural, sendo seus atores orientados por regras formais, estabelecidas através das leis, normas e regulamentos, bem como por regras informais, relacionadas com os hábitos de comportamento praticados pelos atores em determinado ambiente. Deste modo, conforme Mundo Neto e Souza Filho (2005, p. 295), existem dois tipos de agentes de crédito: os "formais (agentes financeiros públicos e privados, cooperativas de crédito) e os informais (agiotas, fornecedores intermediários, parentes, etc.)”.

Portanto, as operações de crédito realizadas fora do âmbito do Sistema Nacional de Crédito Rural são denominadas operações financeiras semiformais e informais, e não apresentam registros, o que dificulta o dimensionamento dos montantes efetivamente transacionados. São exemplos desses tipos de operações: os empréstimos realizados entre produtores e compradores, tratando-se daqueles empréstimos diretos, obtidos pelos produtores e ofertados por particulares ou por pessoas jurídicas ligadas à atividade agropecuária, sendo acessível apenas aos pequenos produtores; e a venda antecipada, em que "o produtor recebe antecipadamente os recursos necessários para viabilizar o plantio, geralmente das agroindústrias e cooperativas", com pagamento realizado em dinheiro ou por meio dos denominados títulos de crédito, principalmente Notas Promissórias Rurais (NPR), emitidas com base em contratos de compra e venda, realizados entre os produtores rurais e os comerciantes. Por fim, existe também a Cédula do Produto Rural (CPR), emitida pelo produtor rural, "que envolve uma promessa de entrega futura de produtos agropecuários, indicando a venda a termo da produção", de modo que "o produtor pode vender sua produção e receber o valor desta no ato de fechamento do contrato" (SILVA, 2006, p. 40-42).

Existem alguns fatores de risco inerentes à atividade rural, tais como o clima, as doenças e pragas e as oscilações presentes no mercado consumidor. Para se protegerem desses perigos, os agentes financeiros utilizam algumas medidas de segurança ao fornecer o crédito para a atividade agrícola, adotadas algumas exigências para a sua concessão, especialmente quando destinado ao agricultor familiar, tais como garantias reais (bens imóveis e entrega 
futura de parte da colheita) e o estabelecimento de altas taxas de juros, além de onerosas condições de pagamento (MUNDO NETO; SOUZA FILHO, 2005).

Por tais motivos e principalmente por ser a atividade agrícola dependente dos fatores naturais e de modificações climáticas, ficou evidenciada, ao longo da história, a necessidade da relevância de um programa de crédito estável, uma vez que as atividades desempenhadas pelo produtor familiar e pelo agricultor, de modo geral, funcionam como instrumento que garante a segurança alimentar do país, bem como a fixação do homem no campo, evitando-se, com isso, o êxodo rural, o inchaço das cidades e o aumento do desemprego urbano (RODRIGUES, 2013).

As exigências que eram feitas pelos agentes financeiros acabavam por onerar demasiadamente o agricultor familiar, acarretando alto índice de inadimplência dos empréstimos realizados por este tipo produtor rural, acentuando a seletividade dos bancos no que diz respeito à concessão de novos financiamentos, restringindo cada vez mais o crédito para a categoria agrícola familiar.

Após diversas reivindicações, o governo passou a formular políticas públicas de crédito especificamente voltadas para o desenvolvimento da agricultura familiar. Devido à sua utilização, ao seu significado e à sua abrangência, a agricultura familiar veio ganhando espaço e importância crescentes nos últimos anos no Brasil. Nesse contexto, surgiu a necessidade de formalizar e regulamentar a atividade agrícola de cunho familiar. Assim, essa modalidade de desempenho da agricultura apenas obteve regulamentação própria em 24 de julho de 2006, sendo-lhe atribuído status de atividade econômica, através da Lei no 11.326, denominada "Lei da Agricultura Familiar", responsável também por institucionalizar o Programa Nacional de Fortalecimento da Agricultura Familiar (Pronaf), no Governo do Presidente Lula, consistindo numa das maiores políticas públicas, em nível federal, voltada especificamente para a agricultura familiar brasileira e que será adiante exposta.

\subsection{O CRÉDITO PARA A AGRICULTURA FAMILIAR E A INSTITUCIONALIZAÇÃO DO PRONAF}

Diante do histórico esquecimento perpetrado pelo poder público desde a época colonial para com os pequenos produtores, foi necessário implementar mudanças e transformações no setor rural brasileiro. O propósito era alavancar a atividade rural por eles desenvolvida e que, apesar de negligenciada, mostrava-se responsável por garantir a 
segurança alimentar do país, além de evitar o êxodo e a pobreza rural, e de contribuir para o desenvolvimento econômico do setor agrário como um todo. Deste modo, a categoria econômica agrícola constituída pelos agricultores familiares passou a gozar de maior atenção do Estado apenas em meados dos anos 1990, através de lutas e reivindicações dos sindicatos e trabalhadores rurais vinculados à Confederação Nacional dos Trabalhadores Rurais e à Central Única dos Trabalhadores (CUT).

Em atendimento a estas exigências, foi criado, através do Decreto ${ }^{\circ} 1.946$, de 28 de junho de 1996, o Programa Nacional de Fortalecimento da Agricultura Familiar (Pronaf), somente vindo a ser institucionalizado pela Lei 11.326, de 24 de julho de 2006, denominada Lei da Agricultura Familiar. Em linhas gerais, através desse programa, os agricultores familiares teriam acesso aos diversos serviços oferecidos pelo sistema financeiro nacional, ou seja, ao crédito e às suas variadas linhas de financiamento.

Desde sua origem, em 1996, o Pronaf recebe novos recursos financeiros oriundos das mais diversas fontes utilizadas pelos bancos oficiais, tais como Secretaria do Tesouro Nacional (STN), Fundos Constitucionais e Fundos de Amparo ao Trabalhador (FAT), além de ter sofrido modificações em sua legislação, positivada no capítulo 10 do Manual de Crédito Rural (MCR) do Banco Central (BACEN). Assim, é pacífico entre os estudiosos do tema (CAZELLA et al., 2004; BÚRIGO, 2007; CARNEIRO, 1997) que a sistemática de concessão de crédito do Pronaf passou a receber contínuas alterações, desde a sua concepção, consistindo numa política em constante evolução, que ainda necessita de transformações para atingir seus objetivos gerais.

Quando do seu surgimento, a fim de delimitar seu público-alvo, o programa atendia os agricultores familiares caracterizados com base nos seguintes critérios: i) possuir, pelo menos, $80 \%$ da renda familiar originária da atividade agropecuária; ii) deter ou explorar estabelecimentos com área de até quatro módulos fiscais; iii) explorar a terra na condição de proprietário, meeiro, parceiro ou arrendatário; iv) utilizar mão de obra exclusivamente familiar; v) residir no imóvel ou em aglomerado rural ou urbano próximo; e vi) possuir renda bruta anual familiar entre R\$ 6 mil e R\$ 110 mil com pelo menos $70 \%$ provenientes da exploração agropecuária e não agropecuária do estabelecimento, ou abaixo de $\mathrm{R} \$ 6$ mil com pelo menos $30 \%$ provenientes da exploração agropecuária e não agropecuária (PÉRSICO, 2011, p. 8).

Neste quesito, o estudo FAO-INCRA (1994) tentou definir, com maior rigor conceitual, a agricultura familiar, constituindo em importante referencial para classificação 
quantitativa dos estabelecimentos considerados familiares à época, a partir de quando foi estabelecida a distinção entre agricultura patronal e agricultura familiar ${ }^{3}$ (CAZELLA et al., 2004, p. 3-4).

O Pronaf é formado por quatro grandes linhas de ação. São elas: a) financiamento de pesquisa e extensão rural, que visa à destinação de recursos financeiros com o objetivo de gerar tecnologias para os agricultores familiares; b) financiamento de infraestrutura e serviços nos municípios, que destina recursos para instalação e melhoria de infraestrutura e serviços essenciais ao desenvolvimento da agricultura familiar nos municípios rurais mais pobres, com grande concentração de agricultores familiares e assentados da reforma agrária; c) financiamento de capacitação e profissionalização de agricultores familiares e técnicos, objetivando a capacitação de técnicos, conselheiros, agricultores familiares para a produção sustentável; e, por fim, d) financiamento de produção, que financia atividades agropecuárias e não agropecuárias desenvolvidas pelos agricultores familiares, objetivando principalmente garantir aos agricultores familiares o acesso ao crédito rural (BITTENCOURT, 2003, p. 111).

Em 1999, novo estudo realizado no âmbito do convênio FAO-INCRA sugeriu a fragmentação dos agricultores familiares beneficiários do programa em grupos distintos, de acordo com o nível de renda bruta familiar anual, permitindo que as regras de financiamentos fossem mais adequadas à realidade de cada segmento social. Deste modo, o Pronaf foi fragmentado em grupos de letras, “A”, "B", “C” e "D". O grupo “A" era direcionado aos agricultores assentados da reforma agrária; o grupo "B" era voltado às famílias de menor renda, isto é, agricultores familiares e remanescentes de quilombos, trabalhadores rurais e indígenas; o grupo "C", para agricultores familiares com renda intermediária; e o grupo "D", para os agricultores de maior renda e economicamente estabilizados (CAZELLA et al., 2004, p. 4-5).

Ressalte-se que a separação dos beneficiários do Pronaf em grupos, especialmente no tocante aos grupos "C" e "D", não fazia parte da concepção inicial do Programa, sendo resultado de problemas enfrentados durante a execução do mesmo.

\footnotetext{
${ }^{3}$ A agricultura patronal é caracterizada pelo fato de que o agricultor incluído nesta categoria atendem aos seguintes critérios: uma maior escolaridade formal; realização do controle de gastos da propriedade e da família de forma desagregada; os dados de suas atividades produtivas são manuseados através de ferramentas gerenciais adequadas, como planilhas, sistemas de custeio e microcomputadores; verificação do controle de informações produtivas de maneira rigorosa e sistematizada; e existência base de dados confiável para tomada de decisões. De seu turno, a agricultura familiar caracteriza-se por: menor escolaridade do agricultor pertencente a esse segmento agrícola; o controle de gastos da propriedade e da família é realizado em conjunto; não possui ferramentas gerenciais adequadas; realiza de maneira rudimentar o controle de informações produtivas, além de não possuir base de dados confiável para tomada de decisões (QUEIROZ; BATALHA, 2005, p. 259).
} 
Adiante, serão expostos, com base em Bianchini (2015), os aperfeiçoamentos que as diversas estruturas do Pronaf sofreram ao longo dos anos desde a sua criação, através do desenvolvimento dos Planos Safras de cada ano, de 2007 (início do segundo Governo Lula) até 2015 (durante o Governo Dilma), onde será possível perceber as modificações que o programa enfrentou até chegar a sua atual concepção estrutural.

Em avaliação do PRONAF no primeiro Governo Lula, entre 2003 e 2006, verificou-se a forte atuação dos agricultores familiares nas negociações e execução dos Planos Safras. Houve crescimento do programa, "agregando-se mais de 900.000 famílias ao sistema de crédito", sendo que os recursos para esta categoria agrícola "aumentaram de 4,5 bilhões na safra 2002/2003 para 7,5 bilhões em 2005/2006”, segundo Bianchini (2015, p. 55).

Na safra 2007-2008 no segundo Governo Lula, foram disponibilizados R\$ 12 bilhões, sendo aplicados R \$ 8,1 bilhões (68\%) em 1.713 .962 contratos (BIANCHINI, 2015, p. 56).

Em resposta à crise financeira mundial, surge na safra 2008-2009 o PRONAF Mais Alimentos, visando a incrementar a produção de alimentos de culturas como o feijão, mandioca, trigo, entre outros. Em 2009, o seguro rural da agricultura passou a cobrir também os financiamentos da modalidade investimento. Além disso, o Plano Safra desse mesmo ano trouxe uma importante inovação para a comercialização de produtos provenientes da agricultura familiar, através da "promulgação da Lei no 11.947, de 16 de junho de 2009, determinando que pelo menos $30 \%$ dos recursos destinados à compra da merenda escolar do Programa Nacional de Alimentação Escolar (PNAE) fossem direcionados para aquisição de produtos da agricultura familiar" (RODRIGUES, 2013, p. 94-95).

Em 2008, os grupos "C", "D" e "E" deixaram de existir e os produtores enquadrados nessas três categorias passaram a ser denominados simplesmente de "agricultores familiares" ou Grupo Variável, permitindo ao agricultor optar pelo valor de financiamento e taxa de juros que desejasse (CONTI; ROITMAN, 2011).

Na safra 2009-2010, foram disponibilizados R 15 bilhões, sendo R \$ 12,6 bilhões (84\%) realmente aplicados em 1.752 .988 contratos. Nesse plano, também foi criado o selo da agricultura familiar (SIPAF) ${ }^{4}$, importante instrumento de acesso aos mercados (BIANCHINI, 2015, p. 59).

\footnotetext{
${ }^{4}$ O Selo da Agricultura Familiar consiste em importante ferramenta, criado pelo MDA, para identificar os produtos oriundos desta categoria. $\mathrm{O}$ selo agrega valor, pois o produto originário da agricultura familiar promove valores cada vez mais exigidos pelos consumidores, quais sejam, sustentabilidade, responsabilidade social e ambiental, valorização da cultura e da produção local.
} 
Na safra 2010-2011, são disponibilizados R 16 bilhões, dos quais R \$ 8,5 bilhões foram destinados para a Linha de Investimentos. O desempenho desse Plano Safra ficou em 83\% (13,3 bilhões), atingindo 1.598 .920 contratos (BIANCHINI, 2015, p. 59).

$\mathrm{Na}$ safra 2011-2012, que marca o início do primeiro Governo Dilma, são disponibilizados $\mathrm{R} \$ 16$ bilhões, sendo $\mathrm{R} \$ 7,7$ bilhões para investimentos e $\mathrm{R} \$ 8,3$ bilhões para custeios (BIANCHINI, 2015, p. 61).

Na safra 2012-2013, por sua vez, foram anunciados R\$ 18 bilhões e aplicados R $\$ 18,6$ bilhões (106\%). Também foram lançadas linhas de crédito emergencial de investimento em função da seca no Nordeste. Os bons preços da agricultura provocaram este aumento da demanda, fazendo com que, pela primeira vez, o recurso aplicado fosse maior do que o disponibilizado. O número de contratos realizados nessa safra ficou em 2.141.262.

Na safra 2013-2014, foi anunciada a liberação de R 21 bilhões, tendo sido aplicados, na realidade, $\mathrm{R} \$ 22,3$ bilhões, i.e., $105 \%$ em relação ao disponibilizado. Foram realizados 1.903.524 contratos. O enquadramento dos agricultores familiares passa a ser definido pelo critério de renda bruta, e o limite passa para $\mathrm{R} \$ 360.000,00$. O limite de crédito de custeio passa de $\mathrm{R} \$ 80$ mil para $\mathrm{R} \$ 100$ mil, e há a manutenção do direito à aposentadoria rural ao agricultor familiar empreendedor (BIANCHINI, 2015, p. 63).

$\mathrm{Na}$ safra 2014-2015, são liberados $\mathrm{R} \$ 24,1$ bilhões e aplicados $\mathrm{R} \$ 23,9$ bilhões, distribuídos em 1.899.423 contratos. Nesse plano, surgiu uma nova linha de crédito, o Pronaf Produção Orientada, voltada para as regiões Norte, Nordeste e Centro-Oeste, com assistência técnica gratuita, inserida no crédito, de R \$1.100,00 por ano no Nordeste, Centro-Oeste e de R\$ 1.500,00 por ano no Norte, em três anos. Ainda, foi anunciada a criação da Agência Nacional de Assistência Técnica e Extensão Rural (Anater), já autorizada pela Lei n. ${ }^{\circ} 12.897$ de 18 de dezembro de 2013. Na safra 2015-2016, são anunciados R 28,9 bilhões, sendo R \$ 26 bilhões com as regras do Pronaf. Houve também a elevação das taxas de juros, negativas em relação à inflação, mas superiores em relação à safra anterior, além do fortalecimento da agroindústria familiar, ampliação do Mercado Institucional para a agricultura familiar com cota de no mínimo 30\% nas compras de alimentos da administração federal (BIANCHINI, 2015, p. 64-65).

As modificações periódicas enfrentadas pelo Pronaf, verificadas principalmente entre os anos de 2013 até o início de 2016, demonstraram a preocupação dos governos populares e desenvolvimentistas de Lula e Dilma em garantir o atendimento das necessidades dos agricultores familiares. Esses ajustes constantes realizados no programa são oriundos de 
reivindicações dos produtores, cooperativas e sindicatos representativos, pois o avanço na concessão do crédito representa o fortalecimento do setor agrícola familiar. Assim, algumas alterações decorrentes do crédito rural Pronaf contribuem ainda para a produção de alimentos e assistência técnica rural, além de fornecer aos agricultores familiares meios de sobrevivência ao sofrerem algum tipo de prejuízo na produção.

\section{O FOMENTO À AgRICULTURA FAMILIAR E O PROGRAMA NACIONAL DE ALIMENTAÇÃO ESCOLAR (PNAE)}

Por ter a agricultura familiar notória relevância no cenário econômico e social brasileiro, destacam-se também as principais políticas públicas desenvolvidas para esse setor rural, especialmente as de fomento, representadas pelas políticas de impulso e estruturação da produção agrícola familiar, tais como o Programa Nacional de Alimentação Escolar (PNAE), o Programa de Aquisição de Alimentos da Agricultura Familiar (PAA), o Programa GarantiaSafra, Seguro da Agricultura Familiar (SEAF) e a Política Nacional de Assistência Técnica e Extensão Rural (PNATER). Dentre as mencionadas políticas de fomento à agricultura familiar, obteve maior destaque, neste trabalho, o PNAE, tendo em vista se tratar de um programa do governo federal que abrange, simultaneamente, agricultura familiar e alimentação adequada, e que será adiante exposto.

O Programa Nacional de Alimentação Escolar (PNAE) consiste em uma das mais importantes políticas públicas de fomento voltada para dois eixos principais, sendo estes seus objetivos primordiais: garantir a alimentação escolar adequada e incentivar a agricultura familiar.

Atualmente, o PNAE (também conhecido como programa da merenda escolar) consiste na transferência de recursos financeiros do Governo Federal, de maneira suplementar, para os Estados, Distrito Federal e Municípios, para aquisição de gêneros alimentícios destinados à alimentação escolar. Sziwelski et al. (2015, p. 222) ressaltam que o PNAE consiste "[...] em importante estratégia para garantia da Segurança Alimentar e Nutricional (SAN), já que promove o Direito Humano à Alimentação Adequada (DHAA), por meio da alimentação escolar". Trata-se, portanto, do único programa brasileiro de cunho alimentar que possui atendimento universalizado, tendo em vista ser uma das políticas alimentares de maior reconhecimento internacional, correspondendo igualmente a um direito 
e dever do Estado, a partir de 1988, no que concerne à alimentação adequada no país (TRICHES; SCHNEIDER, 2010).

O PNAE teve seu marco legal disciplinado através da Lei $\mathrm{n}^{\circ} 11.947$, de 16 de junho de 2009, que dispõe sobre o atendimento da alimentação escolar e do Programa Dinheiro Direto na Escola aos alunos da educação básica ${ }^{5}$. O art. $14^{6}$ da citada Lei determina que, no mínimo, $30 \%$ (trinta por cento) dos recursos financeiros repassados aos Estados, Municípios e Distrito Federal pelo Fundo Nacional de Desenvolvimento da Educação (FNDE) para o Programa Nacional de Alimentação Escolar (PNAE) devem ser obrigatoriamente utilizados na aquisição de gêneros alimentícios provenientes da agricultura familiar (PNAE/FNDE, 2016, p. 4).

Ainda, o parágrafo primeiro do art. 14 da Lei no 11.947/2009 acrescenta que a compra dos gêneros alimentícios da agricultura familiar pode ser realizada mediante Chamada Pública $^{7}$, dispensando-se, portanto, o processo licitatório, desde que atendam a dois requisitos: os preços dos produtos devem ser compatíveis com os vigentes no mercado local, como também devem os alimentos atender às exigências do controle de qualidade previstas nas normas específicas para a matéria.

A partir do disposto em lei, verifica-se que o PNAE é uma política pública que abrange tanto a melhoria da alimentação escolar aos alunos de escolas públicas da educação básica do Brasil como também estimula a agricultura familiar nacional, por meio da obrigatoriedade, determinada em lei, de um percentual mínimo (30\%) dos recursos financeiros transferidos ser destinado à compra de produtos agrícolas familiares.

Nessa perspectiva, a aquisição de gêneros da agricultura familiar para a alimentação escolar está regulamentada pela Resolução CD/FNDE no 26, de 17 de junho de 2013

\footnotetext{
${ }^{5}$ No âmbito do PNAE, a educação básica abrange a educação infantil, o ensino fundamental, o ensino médio e educação de jovens e adultos, matriculados em escolas públicas, filantrópicas e em entidades comunitárias (conveniadas com o poder público) (FNDE, 2017b).

${ }^{6}$ Lei n $^{\circ}$ 11.947/2009, art. 14: "Do total dos recursos financeiros repassados pelo FNDE, no âmbito do PNAE, no mínimo 30\% (trinta por cento) deverão ser utilizados na aquisição de gêneros alimentícios diretamente da agricultura familiar e do empreendedor familiar rural ou de suas organizações, priorizando-se os assentamentos da reforma agrária, as comunidades tradicionais indígenas e comunidades quilombolas".

${ }^{7}$ O Manual de Aquisição de Produtos da Agricultura Familiar para a Alimentação Escolar (PNAE/FNDE, 2016, p. 18) explica que a aquisição de produtos da agricultura familiar para o PNAE através de chamada pública consiste na melhor maneira de atender às especificidades presentes na aquisição da agricultura familiar. Entendese que a chamada pública seria a ferramenta mais adequada, por contribuir para o cumprimento das diretrizes do PNAE no que diz respeito à priorização dos recursos produzidos no âmbito local, de modo a fortalecer os hábitos alimentares, assim como a cultura local e a própria agricultura familiar, fatores fundamentais para garantia da segurança alimentar e nutricional. Logo, a chamada pública deve conter todas as informações necessárias quantidades, cronograma de entrega dos alimentos, locais de entrega, etc. - para que os fornecedores formulem corretamente seus projetos de venda.
} 
(atualizada pela Resolução CD/FNDE $\mathrm{n}^{\circ}$ 04, de 2 de abril de 2015), que dispõe sobre o atendimento da alimentação escolar aos alunos da educação básica no âmbito do PNAE.

Através do PNAE, verifica-se que vem sendo cada vem mais crescente uma atuação estatal que busca combinar o incentivo à produção agrícola familiar local com a qualificação dos programas alimentares escolares. Consequentemente, pode-se inferir que "a alimentação escolar, que até pouco tempo preocupava-se apenas com a nutrição e a educação do público alvo, passa a ser uma oportunidade de incentivo de determinadas cadeias de abastecimento, influenciando os modelos de desenvolvimento" (TRICHES, 2015, p. 184).

Percebeu-se que a baixa produtividade, o frágil desenvolvimento dos mercados agrícolas e os péssimos resultados nutricionais e educacionais eram mutuamente agravados, sendo fatores determinantes para a insegurança alimentar e a pobreza. Daí a necessidade de políticas públicas, como o PNAE, que combinem alimentação escolar, educação e agricultura familiar, gerando consequências positivas e incremento em todas essas áreas. Logo, é possível afirmar que o PNAE consiste em uma política pública que visa, de modo geral, à promoção do desenvolvimento rural, através da compra de produtos de agricultores familiares, reconhecendo a "unidade produtiva familiar como sistema de produção capaz de fornecer alimentos saudáveis e de qualidade" (NUNES et al., 2014, p. 118). Semelhantemente, Sziwelski et al. (2015) ressaltam que a forma como o PNAE está disposto na legislação gera uma aproximação do programa com a agricultura familiar que favorece o fortalecimento desse tipo de categoria agrícola, contribuindo, assim, para a sustentabilidade e soberania alimentar.

Além disso, o PNAE se apresenta também como instrumento que tenta fixar o homem no campo, na medida em que, ao assegurar um rendimento regular à unidade familiar, acaba por tornar menos atraente, aos filhos dos agricultores familiares, a busca por melhores condições de renda e emprego nas áreas urbanas, incentivando sua permanência no campo para dar continuidade ao ofício agrícola familiar desempenhado por seus pais, fortalecendo, com isso, a própria agricultura familiar, tendo em vista que contribui para o desenvolvimento do setor rural (NUNES et al., 2014, p. 118).

Ademais, os reflexos da união entre agricultura familiar e alimentação escolar são igualmente sentidos nesta última, de modo a permitir que alimentos saudáveis e com origens regionais, produzidos em núcleo familiar, sejam consumidos pelos alunos da educação básica da rede pública de todo o país. Portanto, através do PNAE é possível unir alimentação adequada, agricultura familiar, educação e combate à pobreza e à fome, além de contribuir para a aproximação entre campo e cidade, objetivando, principalmente, garantir o direito à 
alimentação adequada e fortalecer a agricultura familiar, que consistem, por conseguinte, em instrumentos para garantia da segurança alimentar e nutricional, bem como para o desenvolvimento econômico do país.

\section{O FOMENTO E O CRÉDITO PARA A AGRICULTURA FAMILIAR}

Conforme Battestin e Vieira (2016), há um conjunto de políticas de apoio à produção familiar e à comercialização dos produtos alimentícios, também denominadas "políticas de estímulo à produção" e "políticas de estruturação de demandas". No âmbito da agricultura familiar, as citadas autoras explicam que:

\footnotetext{
O Programa Nacional de Fortalecimento da Agricultura Familiar (Pronaf), o Garantia Safra e os programas de garantia de acesso à água para produção são políticas que dão suporte aos processos de estímulo produtivos; enquanto o Programa de Aquisição de Alimentos (PAA) e Programa Nacional de Alimentação Escolar (PNAE) apoiam os agricultores por meio de um processo de estruturação da demanda. Esses tipos de políticas devem funcionar de forma articulada e integrada, visto que o estímulo à produção e à organização da demanda são duas faces das políticas de promoção do desenvolvimento rural. Muitas inovações foram desenvolvidas pelos diferentes governos ao longo das últimas duas décadas e em quase sua totalidade estas inovações são resultado de um processo intenso de negociações entre organizações de representação da agricultura familiar no âmbito da sociedade civil e governos (BATTESTIN; VIEIRA, 2016, p. 2).
}

Como é possível observar, as supramencionadas autoras explicam que políticas públicas de crédito, como o Pronaf, e as políticas de fomento para a agricultura familiar, como o PNAE, estimulam a produção familiar por meio de processos que unem apoio à produção e organização de demandas, esta última atuando de modo a auxiliar na comercialização e no mercado para os produtos agrícolas familiares, ambas devendo funcionar de maneira harmônica para que obtenham níveis satisfatórios que causem reflexos positivos à atividade desempenhada pelo agricultor familiar, assim como para o desenvolvimento rural.

O Pronaf significa um dos grandes avanços no que diz respeito a políticas públicas agrícolas, consistindo na primeira fonte de crédito de muitos agricultores familiares. Contudo, ainda são percebidas muitas discrepâncias em sua execução, que se manifestam, por exemplo, "na histórica concentração de recursos na região Sul do país; no baixo nível de acesso dos agricultores mais pobres, reunidos majoritariamente na região Nordeste" (BATTESTIN; VIEIRA, 2016, p. 2). 
Mesmo assim, trata-se de um programa que possui grandes avanços, na medida em que: criou "mecanismos de inserção de agricultores pobres na política de crédito"; garantiu "a assistência técnica aos agricultores familiares investindo na qualificação do crédito rural"; promoveu "no interior dos movimentos sociais um debate acerca da quantidade $\mathrm{x}$ qualidade do crédito rural"; fortaleceu, "por meio da tomada de crédito, experiências produtivas agroecológicas, cumprindo com a premissa de produção de alimentos saudáveis ao país" (BATTESTIN; VIEIRA, 2016, p. 2). Destaque também para o PNAE, que possui "recursos suficientes para expandir as oportunidades de mercado e aumentar expressivamente os rendimentos dos agricultores familiares", sendo "responsável pela nutrição de cerca de 45 milhões de alunos em cada um dos, aproximadamente, 200 dias letivos por ano no Brasil" (BATTESTIN; VIEIRA, 2016, p. 2).

Ressalta-se ainda a importância de tratar a fome, a miséria e a pobreza rurais, problemáticas que não deveriam, mas que ainda são muito presentes na atualidade. Aborda-se aqui também a necessidade de fortalecer a segurança alimentar e nutricional brasileira, para que se atinja o desenvolvimento econômico e a soberania alimentar do país, podendo tais objetivos ser alcançados através do estímulo à agricultura familiar, pois essa atividade agrícola contribui notoriamente para o consumo interno brasileiro, influenciando também na garantia de uma alimentação adequada e, consequentemente, na efetivação do direito humano fundamental à alimentação.

Assim, evidencia-se a íntima relação existente entre as políticas públicas de crédito e de fomento à agricultura familiar, demonstrando-se a relevância de ambas para o desenvolvimento não só da própria atividade agrícola alimentar, mas também para o setor rural brasileiro, sendo fatores de contribuição para amenização do cenário de fome e da pobreza no Brasil.

\section{CONCLUSÃO}

O presente estudo teve como objetivo demonstrar a importância das políticas de crédito e de fomento para a agricultura familiar, não apenas para o desenvolvimento da própria atividade agrícola familiar, mas principalmente, buscou associar crédito e fomento, objetivando verificar que ambos, juntos, auxiliam igualmente para o desenvolvimento econômico também do setor rural brasileiro, contribuindo, reflexamente, para a diminuição da fome e da pobreza no Brasil. 
O poder público brasileiro começou a atribuir relevância a agricultura familiar ao perceber sua importância para a segurança alimentar e para o consumo interno do país.

A primeira atitude do governo brasileiro, nessa perspectiva, foi elevar a agricultura familiar ao status de categoria econômica, com a instituição da Lei $n^{\circ} 11.326$, de 24 de julho de 2006, sendo este seu marco regulatório. Daí em diante, emergem as políticas públicas de crédito à atividade agrícola de cunho familiar, a qual figura atualmente como uma das grandes responsáveis pelo desenvolvimento rural brasileiro, garantindo o abastecimento e o consumo interno do país. Em 1996 surge o Programa Nacional de Fortalecimento da Agricultura Familiar (Pronaf), e somente vindo a ser institucionalizada pela Lei $\mathrm{n}^{\mathrm{o}} 11.326$, de 24 de julho de 2006, denominada Lei da Agricultura Familiar.

Nesse contexto, surgem também as políticas de fomento da agricultura familiar, a exemplo do Programa Nacional de Alimentação Escolar (PNAE), regulamentado pela Lei no 11.947, de 16 de junho de 2009, onde seu art. 14 diz que, no mínimo, 30\% (trinta por cento) dos recursos financeiros repassados aos Estados, Municípios e Distrito Federal pelo Fundo Nacional de Desenvolvimento da Educação (FNDE) para o Programa Nacional de Alimentação Escolar (PNAE) devem ser obrigatoriamente utilizados na aquisição de gêneros alimentícios provenientes da agricultura familiar.

Portanto, é possível verificar que as políticas de crédito e de fomento destinadas à agricultura familiar brasileira são grandes responsáveis por promover o desenvolvimento econômico da atividade agrícola alimentar, do setor rural brasileiro, bem como por garantir, ao menos de forma mínima, a segurança alimentar e a alimentação adequada, direitos sociais previstos constitucionalmente, uma vez que os alimentos produzidos pela agricultura familiar são os responsáveis majoritários pelo abastecimento interno brasileiro.

\section{REFERÊNCIAS}

BATTESTIN; Simone; VIEIRA, Izabelle. Políticas públicas para campo e combate à pobreza rural no Norte e Nordeste: um olhar sobre o peixe, a vara e o rio. Centro Internacional de Políticas para o Crescimento Inclusivo, nº 53, ISSN 2358-1379, mai. 2016. Disponível em: http://www.ipcundp.org/pub/port/PRB53_Politicas_publicas_para_campo_e_o_combate_a_pobreza_rural_n o_Norte_e_Nordeste_um_olhar_sobre_o_peixe_a_vara_e_o_rio.pdf. Acesso em: Jan. 2017.

BIANCHINI, Valter. Vinte anos do PRONAF, 1995-2015: avanços e desafios. Brasília-DF: SAF/MDA, 2015. 
BITTENCOURT, G. A. Abrindo a caixa preta: o financiamento da agricultura familiar no Brasil. Dissertação (Mestrado em Economia). Instituto de Economia, Universidade Estadual de Campinas, Campinas, 2003. Disponível em:

<http://www.bibliotecadigital.unicamp.br/document/?code=vtls000307081>. Acesso em: Mai. 2016.

BRASIL. Lei $\mathbf{n}^{\mathbf{0}}$ 4.829, de 05 de novembro de 1965. Institucionaliza o crédito rural. Disponível em: <http://www.planalto.gov.br/ccivil_03/leis/L4829.htm>. Acesso em: Mai. 2016.

Lei $\mathbf{n}^{\mathbf{0}}$ 11.326, de 24 de Julho de 2006. Estabelece as diretrizes para a formulação da Política Nacional da Agricultura Familiar e Empreendimentos Familiares Rurais. Legislação do Planalto. Disponível em: <http://www.planalto.gov.br/ccivil_03/_ato20042006/2006/lei/111326.htm>. Acesso em: Mai. 2016.

Lei $n^{0}$ 11.947, de 16 de junho de 2009. Dispõe sobre o atendimento da alimentação escolar e do Programa Dinheiro Direto na Escola aos alunos da educação básica; disciplina aquisição de produtos alimentícios da agricultura familiar para a merenda escolar e dá outras providências. Legislação do Planalto. Disponível em:

http://www.planalto.gov.br/ccivil_03/_ato2007-2010/2009/Lei/L11947.htm. Acesso em: Mai. 2016.

BÚRIGO, Fábio Luiz. Cooperativa de crédito rural: agente de desenvolvimento local ou banco comercial de pequeno porte?. Chapecó-SC: Argos, 2007.

CARNEIRO, Maria José. Política Pública e Agricultura Familiar: uma leitura do Pronaf. Estudos Sociedade e Agricultura, Rio de Janeiro-RJ, n. 8, p. 70-82, abr. 1997. Disponível em: http://r1.ufrrj.br/esa/V2/ojs/index.php/esa/article/view/106/102. Acesso: 15 nov. 2015.

CAZELLA, Ademir Antonio; Et. Al. HISTÓRICO, CARACTERIZAÇÃO E DINÂMICA RECENTE DO PRONAF - Programa Nacional de Fortalecimento da Agricultura

Familiar. In: XLII Congresso Brasileiro de Economia e Sociologia Rural. Cuiabá-MT, 2004. Disponível em: <http://www.sober.org.br/palestra/12/06O365.pdf>. Acesso em: 03 jul. 2016.

CAZELLA, Ademir A.; Et. Al (Orgs). Agricultura familiar: multifuncionalidade e desenvolvimento territorial no Brasil. Rio de Janeiro: Mauad X, 2009. ISBN 978-85-7478292-8.

MAFFIOLETTI, Emanuelle Urbano. MICROCRÉDITO: peculiaridades e a democratização do crédito no sistema financeiro nacional. Revista de Direito Mercantil Industrial, Econômico e Financeiro, v. 45, p. 237-262, 2006.

MUNDO NETO, Martin; SOUZA FILHO, Hildo Meirelles. Recursos Financeiros para a Agricultura Familiar. In: SOUZA FILHO, Hildo Meirelles de; BATALHA, Mário Otávio (Orgs.). Gestão Integrada da Agricultura Familiar. São Carlos: EdUFSCar, 2005. ISBN 85-7600-043-1.

NUNES, Márcio Emanuel; et. al. Políticas Agrárias e agrícolas no contexto do desenvolvimento do nordeste: evolução, desafios e perspectivas. Revista Planejamento e 
Políticas Públicas (PPP), no 43, Jul/Dez 2014. Disponível em:

$<$ http://www.ipea.gov.br/portal/index.php?option=com_content\&view=article\&id=24369\&ca tid=179\&Itemid=7>. Acesso em: Jan. 2017.

PEREIRA, Lutero de Paiva. Crédito Rural: Limites da legalidade. $2^{\mathrm{a}}$ ed. Curitiba: Juruá, 2009.

REZENDE, Gervásio Castro de. A agricultura e a reforma do crédito rural. Revista

Brasileira de Economia, Rio de Janeiro, v. 39, n. 2, p. 185-206, abr. 1985. ISSN 0034-7140. Disponível em: <http://bibliotecadigital.fgv.br/ojs/index.php/rbe/article/view/340/7750>. Acesso em: 03 Out. 2016.

RODRIGUES, Sandra Terto Sampaio. O crédito rural promotor do desenvolvimento e o programa nacional de fortalecimento da agricultura familiar (PRONAF). Dissertação. Universidade Federal da Paraíba - UFPB. Programa de Pós-Graduação em Ciências Jurídicas. Mestrado em Direito Econômico. João Pessoa - PB, 2013, 208 p.

SCHUMPETER, Joseph Alois. Teoria do Desenvolvimento Econômico: Uma investigação sobre lucros, capital, crédito, juro e o ciclo econômico. Tradução: Maria Sílvia Possas. São Paulo-SP: Nova Cultura LTDA, 1997. ISBN 85-351-0915-3. Disponível em:

$<$ http://www.ufjf.br/oliveira_junior/files/2009/06/s_Schumpeter_-

_Teoria_do_Desenvolvimento_Econ\%C3\%B4mico_-

_Uma_Investiga\%C3\%A7\%C3\%A3o_sobre_Lucros_Capital_Cr\%C3\%A9dito_Juro_e_Ciclo _Econ\%C3\%B4mico.pdf>. Acesso em: 19 dez. 2015.

SILVA, Fernanda Faria. Distribuição de crédito para agricultura familiar: Um estudo do PRONAF a partir de um indicador de desenvolvimento rural. Dissertação. Universidade Federal de Uberlândia. Instituto de Economia. Programa de Pós-Graduação em Economia. Mestrado em Economia. Uberlândia - MG, 2006, 250 p.

SZINWELSKI, Nádia Kunkel; TEO, Carla Roseane Paz Arruda; GALLINA, Luciara de Souza; GRAHL, Fabiula; FILIPPI, Cimara. Implicações do Programa Nacional de Alimentação Escolar (PNAE) na renda e organização de agricultores familiares. Revista Brasileira de Políticas Públicas, Brasília, v. 5, nº 2, p. 220-239, 2015.

TRICHES, Rozane Márcia. Repensando o mercado da alimentação escolar: novas institucionalidades para o desenvolvimento rural. In: GRISA, Catia; SCHNEIDER, Sergio. Políticas públicas de desenvolvimento rural no Brasil. $1^{\mathrm{a}} \mathrm{ed}$, Porto Alegre: Editora da UFRGS, 2015. 